\title{
Employee Engagement and Achievement Perception of Thai Synchrotron Institute
}

\author{
Naphatthira Mungthanaworakun1, Sarawut Sujitjorn1, Termsak Suwansak², \\ Sirapatsorn Wongthongdee ${ }^{3}$, Yothin Prempraneerach ${ }^{4}$, Khemaree Rugchoochip 5
}

\author{
${ }^{1}$ Synchrotron Light Research Institute (Public Organization), Nakhon Ratchasima, Thailand \\ ${ }^{2}$ Phitsanulok University, Phitsanulok, Thailand \\ ${ }^{3}$ Dhurakij Pundit University, Bangkok, Thailand \\ ${ }^{4}$ King Mongkut's Institute of Technology Ladkrabang, Bangkok, Thailand \\ ${ }^{5}$ Burapha University, Chon Buri, Thailand \\ Email: naphatthira@slri.or.th, sarawut.sujitjorn@slri.or.th
}

\begin{abstract}
How to cite this paper: Mungthanaworakun, N., Sujitjorn, S., Suwansak, T., Wongthongdee, S., Prempraneerach, Y. and Rugchoochip, K. (2020) Employee Engagement and Achievement Perception of Thai Synchrotron Institute. Open Journal of Business and Management, 8, 639-648. https://doi.org/10.4236/ojbm.2020.82038
\end{abstract}

Received: February 6, 2020

Accepted: March 6, 2020

Published: March 9, 2020

Copyright $\odot 2020$ by author(s) and Scientific Research Publishing Inc. This work is licensed under the Creative Commons Attribution International License (CC BY 4.0)

http://creativecommons.org/licenses/by/4.0/

\begin{abstract}
It is a purpose of this work to figure out engagement level of the employees of Synchrotron Light Research Institute (SLRI), a public organization owned by the Government of Thailand. We used a questionnaire survey to explore the issue. Another useful point of interest is employees' perception of organization achievement. So, we launched a 3-part questionnaire to inquire personal information, level of engagement, and perception of achievement. SPSS package was used to analyze the results. It is found that the level of engagement of our employees at large is high. According to the employees' job functions, different groups of employees have different sub-group norms. Scientists and researchers are engaged in creative and challenging jobs; engineers, technicians, and safety personnel are engaged to team, well-planned jobs, success, and reputation; back-office staff are engaged to well-planned jobs, accountability, and ethicality. Accordingly, scientists and researchers perceive the institute as a learning organization (LO), as an effective and efficient factory line for engineers and technicians, and as a high performance organization (HPO) for back-office staff.
\end{abstract}

\section{Keywords}

Employee Engagement, Achievement Perception, Non-Profit Organization

\section{Introduction}

Synchrotron Light Research Institute (SLRI) is a young public organization established by the Government of Thailand in 2008. It is responsible for operating 
and maintaining a synchrotron light source originally constructed by Japan, and later transferred to Thailand as a donation. The light source was used to produce soft x-ray for lithography-based manufacturing process in Japan. Thai scientists had modified it to generate infrared, and soft-to-hard X-ray for scientific research purposes. The institute has three main missions: conducting research, development and innovation (RDI), providing services for academia and industry, and providing upskill and reskill trainings. SLRI's structure composes three major pillars: 1) synchrotron source and experimental facilities, 2) engineering and technical supports, and 3) strategic and administrative supports (or back-office). At present, it has 201 staff members. Among those, 50 are doctoral degree holders in science and engineering, 58 are supportive staff members of strategic and administrative pillars, and the rest 93 are engineers, lab-scientists, and technicians. The proportions of these groups are $24.87 \%, 28.86 \%$ and $46.27 \%$, respectively. More details can be found on our website (www.slri.or.th).

Establishment of the institute as a public organization (non-profit) has been for almost 12 years. We have produced numerous achievements in the fields of material science, particle accelerator, and various engineering innovations. We have been successful in serving industry research professionally. This is evident by our achieved economic impact reported to the government, i.e. an economic value added (EVA) of about 50 million USDs per annum. Theoretically, it is believed that good achievements come from engaged employees. However, sometimes impressive achievements come as a result of incentives alone. So, it is important to measure how well employees are engaged, or outcomes are the results of just attractive incentives the organization provides.

As mentioned earlier the institute has 3 major groups of staff members. Our employees belonging to the first group are doctoral degree holders. They conduct RDI, provide professional services to external users, and some trainings on occasions. Most of them hold the degrees in physics, some in chemistry, biology, and engineering. Since their main tasks concern RDI, working life is quite flexible and results-based. Strong key performance indicators (KPIs) are common to this group. Those include publications, patents, for instance. The second group represents our engineers, technicians, lab-scientists, and safety personnel. Their tasks are to support the first group on various requirements such as instrument operation and maintenance, fabrication of devices and prototypes, and health-safety practice. So, the tasks are day-to-day basis, need a careful plan, and follow the plan to achieve scheduled expectation. Our back-office employees belong to the third group. About half of them serve for routine works, i.e. in finance, HR, and inventory departments, etc. The rest works for strategic departments including organization development (OD), planning, marketing and communication. Majority of this group hold bachelor degrees; some hold masters. The members of the second and third groups have to be responsible for some KPIs of routine-types. Our business development section (BDS) is an exception as the people here are responsible for creating market, helping develop 
professional service contracts, incomes and EVA.

SLRI has 3 groups of employees doing very different things; they might have different perceptions to what the organization has been successful. We thus measure employees' perception of organization achievements. The results will give a picture of sub-group beliefs among our employees, and will be useful for management.

Therefore, the objectives of our work are to find out the levels of our employee engagement, different sub-group belief, and employee perception to organization achievements. We issued questionnaire to 201 employees, all permanent staff. 132 of them responded. According to Krejcie and Morgan's table, this is bound to an acceptable error of 5 percent [1]. We then used SPSS package to analyze the results via F-test, frequency, percentage, mean and SD. This article reports our studies and findings.

\section{Literature Review}

Since our staff members are non-homogeneous, it is interesting to investigate our employee engagement together with their perception to organization achievements as a whole and in separate categories. Engagement of employees is vital for being excellent, and retaining talents [2]. Engaged employees have positive attitude towards their workplace [3], are highly committed to the works and the organizations [4] [5], and help increase good results and productivity [6] [7]. In the contrary, disengaged employees tend to shy away from the organization, and have low performance [2]. From surveys of several thousand companies worldwide by Gallup, it has been evident that engaged employees can help increase productivity of more than $25 \%, 21 \%$ higher in customer satisfaction, $21 \%$ more in profits, company growth of higher than $16 \%$, and decrease employee turnover by $25 \%$ [7].

There has been a body of knowledge on factors influencing employee engagement and organization achievement. These conclude 1) organization image and reputation, 2) pride of in the membership of a particular organization, 3) commitment and devotion of employees to works, 4) valued jobs, 5) challenging jobs, 6) understanding of jobs at hands, 7) clear job procedures, 8) opportunity to learn and grow, 9) quality of work- and personal life, and 10) responses to employees' needs [8] [9] [10] [11]. These factors were considered on the design of our questionnaire.

Organization achievement can be measured in 4 dimensions that are efficiency, effectiveness, being high-performance organization (HPO) and learning organization (LO). Being a HPO ensures sustainable success, while being a LO enables transformation capability or capability to change [12]. Efficiency simply means doing the things right, while effectiveness means doing the right things. Savings in resources, time, and money are the main concerns of efficiency. An organization of high efficiency can manage to reach strategic goals and objectives fast and economical [13] [14] [15]. Doing things effectively is concerned 
with working to complete the job with quantity and quality being met, also reasonable use of resources [15] [16]. Work habitat, employee and customer satisfactions are also important aspects.

A HPO successfully delivers outcomes that meet strategic goals and objectives in a considerable shorter time than an ordinary organization. Recent publication asserts that factors contributing to being a HPO include management quality, employee quality, openness and action orientation, long-term orientation, continuous improvement and renewal [17]. In a HPO, employees are engaged, and adaptively respond to change. Work habitat supports employees to effectively render outcomes. The employees have high satisfactions in jobs, salary, and benefits. Management is transparent, accountable, and ethical. These lead to high employees' commitment, and customer satisfaction and advocacy [18].

Being a LO raises collaboration, growth, and innovation. In such an organization, empowerment and degrees of independency are high. Employees have freedom to create, exchange their knowledge, and their work-life is flexible. Teaming, collaboration, and adaptability of organization to changes are common. People in a LO embrace and learn from failures, though they do not deny risk management [19] [20] [21] [22].

We applied the above definitions, concepts, and facts in the design of our questionnaire. Analyzed responses are expected to reveal how well our employees are engaged, do they have any sub-group norm, and what perceptions they have on the organization achievements.

\section{Methods}

We attempted to study the whole population of our institute since there are only 201 staff members. There are 3 groups of our employees according to their job functions. Employees in the first group are doctoral degree holders; they perform tasks on research, development and innovation, research services and consultancy. Occasionally, they teach to reskill and upskill workforces. Work-life of the first group is quite flexible but result-oriented with strong key performance indicators (KPIs), i.e. rather more competitive. The second group consists of engineers, technicians, lab-assistants, and safety personnel. Their educational qualification ranges from vocational school to master-degree level. They perform tasks that have to strictly meet schedules, mostly in teams. So, their work-life is pretty stable, well planned, and time-effective. Their KPIs stress work effectiveness and efficiency. Back-office staff members belong to the third group. About half of this group performs routine tasks such as those in finance, $\mathrm{HR}$, and inventory departments. Another half is responsible for routine and non-routine tasks. Their routine tasks include planning, jobs monitoring, and risk management. Organization development, marketing, and communication are non-routine tasks that the people in this group are responsible for. Educational qualification of the people in the third group ranges from bachelor to master degrees in social sciences, accounting, IT, business and management. 
Their work-life follows common hours from 08.30 - 16.30 daily.

Our questionnaire contains 3 parts: 1) inquire about personal information, 2) 9 questions to inquire about engagement with rating scale of 1 to 4 corresponding to least agreeable to most agreeable), and 3) 26 questions with a similar rating scale to inquire about perception of achievements in 4 dimensions as an efficient, an effective, a learning, and a high performance organizations, respectively.

Concerning the design of our engagement questionnaire, we mainly adopted the recommendations by the IES' Diagnostic Tool. They cover training, development and career, immediate management, performance and evaluation, communication, equal opportunities and fairness, pay and benefits, health and safety, co-operation, family friendliness, and job satisfaction [8]. Partly, we adopted the factors found from surveys by Hewitt Associate [10], which are company practices, work, total rewards, quality of life, opportunities, and people. Interestingly, the company deliberately elaborates detailed experiences influencing engagement behaviors as follows: company practices dimension includes communication, performance assessment, and enterprise reputation; work dimension includes work tasks, resources, processes, and sense of accomplishment; total rewards dimension includes pay, benefits, and recognition; quality of life dimension includes work life balance, and physical work environment; opportunities dimension includes career opportunities, learning and development; people dimension includes manager, co-workers, senior leadership, and valuing people. Eventually, we came up with the following engagement factors to be assessed: enterprise reputation, proud of membership, work commitment, job satisfaction, valued and challenging jobs, contributions to workplace, learning and growth, work-life balance, and workplace responsiveness.

To assess sub-group beliefs in terms of employees' perceptions of organizational achievements, we categorized our questionnaire into 4 sections namely efficient, effective, learning, and high performance organizations, respectively. For an efficient organization, responders scored their perceptions on customer satisfactory, quality of services, quality of operations, and resource utilization. Responders scored their perceptions on strategic goals achievement, employee satisfaction, work environment, and resource availability for an effective organization. For a high performance organization, responders expressed their perception through scoring on leadership, strategy, organizational ethics, work evaluation, and ability to deliver services beyond customers' expectation. For the last category of being a learning organization, responders scored the following factors: coworkers being open-minded, self-improvement, teaming, analytical thinking, creativity and innovation, exchange of ideas, knowledge sharing, failure embracing workplace, capability development, involvement in work improvement and development of vision.

We used SPSS package to analyze the results, and considered frequency, percentage, mean, and SD values. We also applied the F-test to find-out intergroup differentiation. For reliability test of our tool, the questionnaire was revised by 4 
experts composing of $2 \mathrm{HR}$, and 2 engineering professors. The revised form was launched as a pre-test to 24 staff members of Thailand Institute of Nuclear Technology (TINT) to acquire the cronbach alpha coefficient. TINT is a similar kind of organization doing research and services in nuclear science and technology. The size of organization is about two times larger than our institute. They also have 3 groups of employees, i.e. scientists and researchers, engineers and technicians, and back-office staff. The group of 24 was the mixture of these 3 groups of their staff selected by TINT's HR department. Among them, 8 were scientists and researchers; the other 8 and 8 were engineers and technicians, and back-office staff, respectively. We obtained a high reliability level of 0.9397 .

\section{Results}

We received 132 responses from our survey. Among those, 30 are scientists and researchers (22.73\%); 58 are engineers and technicians (43.94\%), and 44 are back-office staff (33.33\%). Table 1 summarizes the numerical results indicating engagement. As indicated by the mean values, the employees at large are well engaged at the level of about $3.0-3.19(80 \%-81 \%)$. When we looked more closely into the details of the obtained data, we found that scientists and researchers are mostly engaged to valued and challenging jobs (mean of 3.5), engineers and technicians are more engaged to work commitment and teaming (mean of 3.55), and back-office staff are well engaged to reputation and the pride of organization (mean of 3.52). For groups 1, 2 and 3, respectively, the employees express lower averaged scores on organization responses to demands, opportunity to learn and grow, and similarly (means of 2.7, 2.79 and 2.81, respectively). In addition, the F-test score is 1.681, and sig (2-tailed) is 0.190 .

Table 2 summarizes the mean, SD, F-test, and sig (2-tailed) values for employees' perception of organization achievements. Four perceptive dimensions are learning, high performance, effective, and efficient organizations. The F-test scores for each dimension are $0.218,6.170,4.909$, and 1.749 , respectively. The sig (2-tailed) scores are $0.804,0.003,0.009$, and 0.178 for the respective dimension.

\section{Discussions and Findings}

Referring to Table 1, although the mean scores from employee groups are not equal, the sig (2-tailed) value is greater than 0.05 . It can be concluded that the employees at large are engaged at a high level, and they feel very much the same.

Table 2 presents the data for the perception of achievement. Scientists and researchers, the $1^{\text {st }}$ group, score their perception as the means of $(3.00,2.71,2.88$,

Table 1. Scoring for employee engagement.

\begin{tabular}{cccccc}
\hline Employee Groups & $\mathrm{n}$ & $\bar{X}$ & SD & F & Sig. \\
\hline Scientists \& researchers & 30 & 3.0125 & 0.45998 & 1.681 & 0.190 \\
Engineers \& technicians & 58 & 3.1860 & 0.46147 & & \\
Back-office staff & 44 & 3.1061 & 0.34247 & & \\
\hline
\end{tabular}


Table 2. Scoring for achievement perception among employee groups.

\begin{tabular}{ccccccc}
\hline $\begin{array}{c}\text { Achievements } \\
\text { Perception }\end{array}$ & Employee Groups & $\mathrm{n}$ & $\bar{X}$ & SD & F & Sig. \\
\hline LO & Scientists \& researchers & 30 & 3.00 & 0.411 & 0.218 & 0.804 \\
& Engineers \& technicians & 58 & 3.02 & 0.455 & & \\
\multirow{2}{*}{ HPO } & Back-office staff & 44 & 3.06 & 0.325 & & \\
& Scientists \& researchers & 30 & 2.71 & 0.527 & 6.170 & $0.003^{* *}$ \\
& Engineers \& technicians & 58 & 3.03 & 0.451 & & \\
\multirow{2}{*}{ Effectiveness } & Back-office staff & 44 & 3.07 & 0.452 & & \\
& Scientists \& researchers & 30 & 2.88 & 0.364 & 4.909 & $0.009^{* *}$ \\
& Engineers \& technicians & 58 & 3.16 & 0.375 & & \\
& Back-office staff & 44 & 3.00 & 0.305 & & \\
Efficiency & Scientists \& researchers & 30 & 2.83 & 0.411 & 1.749 & 0.178 \\
& Engineers \& technicians & 58 & 2.99 & 0.478 & & \\
& Back-office staff & 44 & 2.99 & 0.356 & & \\
\hline
\end{tabular}

2.83) for (LO, HPO, effectiveness, efficiency), respectively. An interpretation is that the $1^{\text {st }}$ group of employees perceive SLRI as a LO, and they are engaged more to creative and challenging jobs. As this is a nature of doing research and innovation. Engineers and technicians, the $2^{\text {nd }}$ group, present their scores in a similar manner as follows: $(3.02,3.03,3.16,2.99)$. The group perceives SLRI as an effective organization, and is committed to works and successes. For the last group, they score being a HPO with the highest mean of 3.07. This tells us that the $3^{\text {rd }}$ group, back-office staff, perceives SLRI as a HPO, and is committed to well-planned jobs and efficiency. The scores actually reflect that the management has been successful in implementing HR strategies. Even though the employees have different sub-norms, they are well engaged as a whole. However, the lower means mentioned in section 4 tell us that we shall have to pay more attention to those issues. These include providing employees more opportunities to learn and grow, and tightening internal communication. We need to find out more on the issue of responses to demands because in one hand this could mean our organization responses are not good enough or not meeting their standards. On the other hand, it could mean such responses are not quite a factor contributing to their engagement, or no matter how good responses are, they will not be engaged due to this reason.

The sig (2-tailed) values in Table 2 indicate that difference in employees' achievement perception is true only in 2 dimensions, i.e. high performance and effectiveness. Engineers, technicians, lab-assistants, and safety personnel are highly effective teams. They are very determined and committed to works and the workplace. Commitment of back-office staff makes the offices become HPOs since they are well planned, resource mindful, accountable, and ethical.

Another finding is that SLRI as a single organization has 3 sub-group norms 
according to the job natures. This is like having 3 different business units under one enterprise. One is research laboratories that provide research and professional services to customers. The second is similar to a factory line, and the third is a HPO. Managing such an enterprise is a complex task, and requires different approaches. So, a challenge to the CEO is an effective management to balance paradox and conundrum.

The work presented so far is rather limited in scope. It aims to disclose the buried issues of employee engagement, and employees' perception of the organizational achievements, particularly for the Synchrotron Light Research Institute in Thailand. The institute is an organization for advanced physics in photon science. The conclusion drawn is by no means to be applied in general to any enterprises. It may give something like a mirror image to other institutes of the similar kind, i.e. institutes of advanced physics, scientific services companies, high-tech research laboratories, etc. Nonetheless, our questionnaire approach can be applied by those enterprises, while a new survey is to be launched, and results be interpreted. Conducting engagement surveys for many scientific institutes and have the results compared will be useful for social science community. To overcome the shortcomings, we suggest that other organizations of the similar kind redesign their questionnaire, and apply some commercial software to test the questionnaire validity that will be more accurate.

\section{Conclusion}

Synchrotron Light Research Institute (SLRI) in Thailand is a public organization owned by the government. So far, the institute has performed exceptionally well which is evident by numerous national and international awards it has received (www.slri.or.th). From the viewpoint of an organization, it is important for the CEO to know whether the employees are engaged, or they only produced impressive outcomes because of attractive incentives alone. We launched questionnaire to our permanent staff members, and 132 from 201 responded. Based on the results presented so far, our employees at large are engaged at a high level. They tend to have sub-group norm. Scientists and researchers are engaged in challenging and creative jobs. Their perception of achievement is in terms of learning organization, in which people are more flexible and exposed to learning and growth habitat. Engineers, technicians, and safety personnel are engaged in teaming, and meet-the-schedule jobs. They are highly engaged in work and organization commitments. They feel proud of being a significant part of the institute. Their jobs are like factory lines, and they perceive SLRI as a highly effective organization. Back-office personnel are very well planned to perform their supportive jobs. They are so determined to deliver job-outcomes efficiently and effectively. Their management is transparent, accountable, and ethical. They perceive achievements as a high performance organization, and they have pride in the purpose of being SLRI. Due to the existing sub-group norms reflecting the nature of SLRI like having 3 different business units under one single enterprise, 
a challenge to the present and the future CEOs is an effective management to balance paradox and conundrum.

\section{Acknowledgements}

The authors thank their colleagues at SLRI for an active participation of the study, and the staff members of TINT who helped verify our questionnaire research tool. We are also thankful for anonymous reviewers for their valuable comments.

\section{Conflicts of Interest}

The authors declare no conflicts of interest regarding the publication of this paper.

\section{References}

[1] Krejcie, R.V. and Morgan, D.W. (1970) Determining Sample Size for Research Activities. Educational and Psychological Measurement, 30, 607-610. https://doi.org/10.1177/001316447003000308

[2] Sundaray, B.K. (2011) Employee Engagement: A Driver of Organizational Effectiveness. European Journal of Business and Management, 3, 53-60.

[3] Sheldon, M.E. (1971) Investments and Involvements as Mechanisms Producing Commitment to the Organization. Administrative Science Quarterly, 16, 143. https://doi.org/10.2307/2391824

[4] Buchanan, H.B. (1974) Building Organization Commitment-the Socialization of Managers in Work Organization. Administrative Science Quarterly, 19, 533-546. https://doi.org/10.2307/2391809

[5] Gubman, L.E. (1998) The Talent Solution: Aligning Strategy and People to Achieve Extraordinary Results. McGraw-Hill, New York.

[6] Steers, R.M. and Porter, L.W. (1983) Motivation and Work Behavior. McGraw-Hill, New York.

[7] The Gallup Organization (2013) How Employee Engagement Drives Growth. https://www.gallup.com/workplace/236927/employee-engagement-drives-growth.as px

[8] Gubman, E.L. (2003) Increasing and Measuring Engagement. http://www.Gubmanconsulting.com/wring-increasing.html

[9] Institute for Employment Studies (2004) What Is Engagement? http://www.employment-studies.co.uk/summary/summary.php?id=408

[10] International Survey Research (2004) Creating Competitive Advantage from Your Employees: A Global Study of Employee Engagement. http://www.ISRINSIGHT.com

[11] Hewitt Associates (2011) Trends in Global Employee Engagement. http://www.aon.com/attachments/thoughtleadership/Trends_Global_Employee_En gagement_Final.pdf

[12] Decharin, P. (2006) High Performance Organization (In Thai). Chulalongkorn Business School, Chulalongkorn University, Bangkok.

[13] Millet, J.D. (1954) Management in the Public Service: The Quest for Effective Performance. McGraw-Hill, New York. 
[14] Drucker, P.F. (1995) Innovation and Entrepreneurship. Butterworth Heinemann, Waltham, MA.

[15] Certo, S.C. (2000) Modern Management. Prentice-Hall, Uupper Saddle River, NJ.

[16] Gibson, J.H., John, M.I. and James, H.D. (1982) Organizations: Behavior Structure and Processes. Business Publications, New York.

[17] De Wall, A. (2019) What Makes a High Performance Organization. Professional Publishing, New York.

[18] De Waal, A. (2007) The Characteristics of High Performance Organization. Business Strategy Series, 8, 179-185. https://doi.org/10.1108/17515630710684178

[19] Senge, P.M. (1999) The Fifth Discipline: The Art and Practice of Learning Organizations. Doubleday, New York.

[20] Casey, D. (1996) Managing Learning Organizations. Open University Press, Maidenhead, Berkshire.

[21] Gavin, D.A. (1998) Knowledge Management: Building a Learning Organization. HBR Press, Brighton, MA.

[22] Marquardt, M.J. (2002) Building the Learning Organization: Mastering the 5 Elements for Corporate Learning. Davies-Black, Mountain View, CA. 